\title{
Reoperating after endovascular therapy: A future challenge of cardiovascular surgery
}

\author{
Meghana R. K. Helder, MD, and Hartzell V. Schaff, MD
}

\author{
From the Department of Cardiovascular Surgery, Mayo Clinic, Rochester, Minn. \\ Disclosures: Authors have nothing to disclose with regard to commercial support. \\ Received for publication July 12, 2017; accepted for publication July 17, 2017; available ahead of print Aug 9, \\ 2017. \\ Address for reprints: Hartzell V. Schaff, MD, Division of Cardiothoracic Surgery, Joseph 5-200 St Mary's Hos- \\ pital Mayo Clinic, 1216 Second St SW, Rochester, MN 55902 (E-mail: schaff.hartzell@mayo.edu). \\ J Thorac Cardiovasc Surg 2018;155:523-4 \\ 0022-5223/\$36.00 \\ Copyright (C) 2017 by The American Association for Thoracic Surgery \\ http://dx.doi.org/10.1016/j.jtcvs.2017.07.028
}

In this issue of the Journal, Shijo and colleagues ${ }^{1}$ describe management of a 78-year-old man who was seen with severe mitral regurgitation. Complicating his case was the fact that he had previously undergone endovascular repair of a zone 1 aortic arch aneurysm, with the bare stent portion of the graft extending proximal to the innominate artery on the lesser curvature of the aorta. He also had an extraanatomic bypass from the brachiocephalic artery to the left common carotid and subclavian arteries. Given the hazards of standard ascending aortic crossclamping in this situation, aortic occlusion was accomplished with an endovascular balloon through the right femoral artery. The left femoral artery and right axillary artery were both cannulated for extracorporeal circulation, with clamping of the innominate artery and balloon occlusion of the distal aortic arch for cardioplegic arrest during mitral valve repair.

Shijo and colleagues ${ }^{1}$ are to be congratulated on a novel approach to a difficult clinical situation. What are the alternative methods to consider? Percutaneous treatment of the mitral valve may be, in some ways, an "easier" approach for such a patient. Percutaneous mitral valve repair with the MitraClip (Abbott Laboratories, Abbott, Ill) is often not completely successful, however, and its long-term durability is unknown. ${ }^{2}$ Another alternative would have been to deliver the endovascular balloon antegrade through a pursestring suture in the ascending aorta if the anatomy allowed this. ${ }^{3}$ This would avoid the need for right axillary cannulation, because the balloon could be inflated proximal to the origin of the brachiocephalic artery.

A more traditional method to consider in the situation that Shijo and colleagues ${ }^{1}$ encountered would be mitral valve repair without aortic clamping with fibrillatory arrest, or even repair with a beating heart. Fibrillatory arrest with hypothermic perfusion has been used for decades in mitral surgery and is relatively straightforward as long as there is not more than a mild degree of aortic regurgitation. ${ }^{4-6}$ Others have published good outcomes for mitral valve procedures performed with a beating heart without periods of fibrillation or cardioplegic arrest. The key to

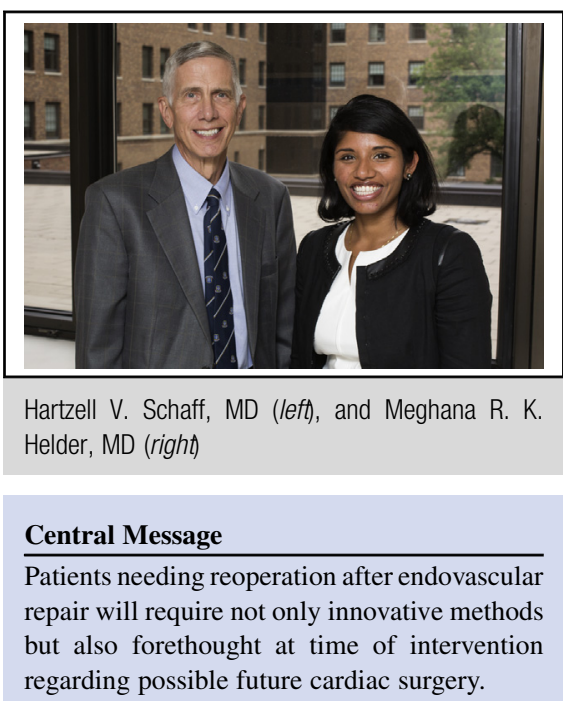

See Article page 520 .

this technique is careful venting of the left ventricle..$^{7-9}$ Finally, hypothermic circulatory arrest could be used if exposure of the valve is poor with the methods discussed or if an additional aortic valve procedure is necessary. ${ }^{10}$

In summary, endovascular therapy has steadily moved proximally in the thoracic aorta, and, as illustrated by this case, we can anticipate challenging clinical problems related to concomitant cardiac diseases. Surgeons must continue to use novel methods when open surgical approaches are indicated and not default to percutaneous or endovascular options just because they are technically simpler, especially if they are less effective than standard procedures. This case also highlights the importance of forethought regarding possible valvular disease in patients undergoing diagnostic evaluation for endovascular aortic repair.

\section{References}

1. Shijo T, Marumoto A, Iwata K. Stent-graft balloon occlusion with selective cerebral perfusion for cardiac surgery after proximal aortic arch stent grafting: a case report. J Thorac Cardiovasc Surg. 2018;155:520-2.

2. Maisano F, Franzen O, Baldus S, Schäfer U, Hausleiter J, Butter C, et al. Percutaneous mitral valve interventions in the real world: early and 1-year results from the ACCESS-EU, a prospective, multicenter, nonrandomized post-approval study of the MitraClip therapy in Europe. J Am Coll Cardiol. 2013;62:1052-61.

3. Erath HG Jr, Stoney WS Jr. Balloon catheter occlusion of the ascending aorta. Ann Thorac Surg. 1983;35:560-1.

4. Glenn WW, Toole AL, Longo E, Hume M, Gentsch TO. Induced fibrillatory arrest in open-heart surgery. $N$ Engl J Med. 1960;262:852-6.

5. Hollatz A, Balkhy HH, Chaney MA, Neuburger PJ, Gerlach RM, Guy TS. Robotic mitral valve repair with right ventricular pacing- 
induced ventricular fibrillatory arrest. $J$ Cardiothorac Vasc Anesth. 2017;31:345-53.

6. Umakanthan R, Petracek MR, Leacche M, Solenkova NV, Eagle SS, Thompson A, et al. Minimally invasive right lateral thoracotomy without aortic cross-clamping: an attractive alternative to repeat sternotomy for reoperative mitral valve surgery. J Heart Valve Dis. 2010;19:236-43.

7. Thompson MJ, Behranwala A, Campanella C, Walker WS, Cameron EW. Immediate and long-term results of mitral prosthetic replacement using a right thoracotomy beating heart technique. Eur J Cardiothorac Surg. 2003;24:47-51; discussion 51.
8. Pasic M, Sündermann S, Unbehaun A, Kempfert J, Jacobs S, Falk V. Beating heart mitral valve surgery: results in 120 consecutive patients considered unsuitable for conventional mitral valve surgery. Interact Cardiovasc Thorac Surg. 2017:25:541-7.

9. Salhiyyah K, Taggart D. Beating-heart valve surgery: a systematic review. Asian Cardiovasc Thorac Ann. 2009; 17:650-8.

10. Aranki SF, Nathan M, Shekar P, Couper G, Rizzo R, Cohn LH. Hypothermic circulatory arrest enables aortic valve replacement in patients with unclampable aorta. Ann Thorac Surg. 2005;80:1679-86; discussion 1686-87. 